Type of the Paper (Review.)

\title{
Comparison of EO4Agri recommendations with in-depth literature review
}

\author{
Karel Charvat ${ }^{1}$, Vincent Onckelet ${ }^{2}$ and Hana Kubickova ${ }^{2, *}$ \\ 1 Wirelessinfo; charvat@wirelessinfo.cz \\ 2 Plan4all z.s.; vincent.onckelet@gmail.com; hana.kubickova@plan4all.eu \\ * Correspondence: hana.kubickova@plan4all.eu
}

\begin{abstract}
Copernicus is Europe's space-based Earth monitoring asset, which consists of a complex set of systems that collect data from different sources: remote sensing satellites (RS) and in-situ sensors such as ground stations, airborne and marine sensors. This study was originally prepared for the needs of the Czech agricultural community, where we provided an in-depth analysis of articles related to Earth observation in precision agriculture. At a later stage, we extended this study by comparing the recommendations of the European EO4Agri project and scientific articles published in MDPI. We had two important objectives, one was to validate the results of the EO4Agri project and the other was to look for gaps in current research and community needs. To recognize the importance of using Sentinel 1 data, we also added a specific analysis of methods for data fusion of Sentinel 1 and Sentinel 2 data.
\end{abstract}

Keywords: Agriculture, Copernicus, Sentinel 1, Sentinel 2, MPDI, Literature Review, EO4Agri

\section{Introduction}

\subsection{Basic literature overview}

Today, climate change is having an impact on all ecosystems. Scientists are now certain that man-made emissions have dangerously and permanently altered our planet [1]. It also threatens the balance of global food production. In addition, the world's population continues to grow (9.7 billion people in 2050 according to the United Nations). Between climate change, decreasing water supplies for irrigation, increasing production costs and the general reduction of the agricultural workforce over the last decades, humanity is now facing great challenges. Monitoring land use change has become very important in recent years as it allows better anticipation of the various hazards that can impact agriculture and biodiversity but also to limit the impacts of land use [2]. Only one third of the Earth's surface is covered by land (about 140 million $\mathrm{km}^{2}$ ). Forest ecosystems contribute to maintaining biological diversity, regulating the water cycle, storing carbon and other ecological functions [2]. However, the main causes of biodiversity loss are land cover change and human disturbance, including land use degradation or intensification and urbanisation. A balance must be found to provide services to a growing humanity while respecting and preserving the environment in a sustainable manner. In agriculture, yields are influenced by a multitude of factors that interact with each other and with the environment, such as fertiliser application, irrigation management, soil attributes and climate [3]. Other factors such as pests, pathogens, weeds and natural disasters can also have a negative impact on agricultural productivity and yield [4].

Precision agriculture (PA) is defined as the management of agriculture, forestry and livestock based on the observation, measurement and response of all quantitative and qualitative inter- and intra-field variables that act in agriculture [5]. This is done in order to define action plans for the whole farm management, with the aim of optimising yields taking into account climatic, environmental, economic, productive and social sustainability. Pierce and Novak [6] define PA as "doing the right thing, in the right place, at the right time". Unlike conventional agriculture, PA recognises that each field is not uniform and that its specific needs must be taken into account.

PA has a long list of demonstrated benefits, which can be summarized as follows:

- Maximising yields;

- Identification of plant stress;

- Constant monitoring of crops with the possibility of implementing targeted actions; 
- Reduction of intra-field variability;

- Reduction in the cost and time of farming operations;

- Reducing the environmental impact of farms;

- Optimisation of fertiliser, pesticide and water use;

For a precision farming system to be effective, it is necessary to collect a large amount of data, which can be done by nearby or distant sensors. This collected data is then interpreted and evaluated from an agronomic point of view so that it can be applied manually or as inputs to variable rate machines (VRTs), which are able to perform prescribed actions automatically [5]. Data collection, research methods and model-building capabilities have advanced considerably with progress in satellite remote sensing and computer technology. Recent advances in remote sensing and artificial intelligence, for example, allow precise quantification of phenotypic information at the field level and the integration of big data into predictive and prescriptive management tools [7]. Advances in remote sensing can be used in many areas. Research in recent years has highlighted a number of potential applications. This review focuses on the uses of the Copernicus Sentinel-1 and Sentinel-2 satellites through several publications.

The two satellites launched as part of the European Union's Copernicus earth observation initiative are using highresolution radar and optical systems to monitor the earth's biophysical attributes and land cover (ESA 2014).

Synthetic Aperture Radar (SAR) has the benefit of operating at wavelengths unaffected by cloud cover or lack of illumination, and can collect data at any time of day or night, in any weather.

Sentinel-1 can provide reliable and repeatable monitoring of a vast area because to its C-SAR equipment.

The twin Sentinel-2 satellites maintain SPOT and LANDSAT image data continuity and contribute to multispectral Earth observations. Copernicus satellites are used for a variety of purposes, including land management, agriculture, forestry, disaster monitoring, humanitarian relief, risk mapping, and security.

In their study, [2] propose an alternative method based on conventional change detection techniques combined with supervised maximum likelihood classification (MaxLike) of satellite images to generate consistent land use and land cover maps. According to them, satellite observations with wide spatial coverage and short revisit times have proven to be an effective tool for monitoring vegetation growth.

The creation of a new approach for monitoring vegetation growth and collecting vegetation phenology from remotely sensed vegetation index (VI) time-series data is proposed in their paper. They worked with data collecting, processing, and analysis as well. Satellite imagery offers advantages such as the free availability of remote sensing data (Landsat, Sentinel, ASTER, among others). Other advantages are that satellite imagery represents temporal data in different electromagnetic spectral bands (multispectral data), the temporal resolution of the freely available sensors (16 days, on average), and the spatial resolution of the images in the visible and infrared bands (Landsat $30 \mathrm{~m}$, Aster 15-30 m, Sentinel $10-20 \mathrm{~m}$ ) is suitable for studies at local or regional scales.

Satellite remote sensing can also be used to assess crop losses due to floods. In their study,[8] review case studies that have used remote sensing data for different aspects of crop loss assessment due to floods. Indeed, it is one of the most important natural hazards, causing considerable damage to crops worldwide. In addition, the impacts of climate change may cause frequent flooding.

In the past, the assessment of crop losses due to floods was based on surveys and the results remained very general. Recently, the number of case studies has increased due to the availability of remote sensing data. Moderate Resolution Imaging Spectroradiometer (MODIS) and Landsat are the main sources of optical remote sensing data for flood damage assessment.

In recent years, remote sensing-based vegetation indices (VIs) have been widely used for crop damage assessment, including NDVI, EVI and LAI. Many case studies also rely on microwave remote sensing data, due to the inability of optical remote sensing to see through clouds. The recent availability of free Sentinel-1 Synthetic Aperture Radar (SAR) data will help advance the assessment of crop damage from flooding and overcome this problem.

Although no use of Sentinel-1 data was reported in the case studies selected in the article, it is quite possible that Sentinel-1 will be used in the near future due to its free availability. Sentinel-1 provides multi-polarised C-band SAR data, which is suitable for both flood mapping and crop condition monitoring [9], even in overcast conditions.

In their study, [10] aimed to identify the potential of Sentinel-2 satellites to monitor vine growth at a regional scale in a wine-growing area during the 2019 growing season. Satellite remote sensing platforms provide accurate temporal and spatial information for viticulture and this is improving all the time. 
The data delivered by these satellites show great efficiency in monitoring management applications (tillage and pruning). The days of phenological events of the vineyard plots were also recorded and showed a correlation with the altitude of the plots for bud break, flowering, veraison and harvest. The researchers note that the results are reasonable in terms of the relationship between altitude and temperature and the effect on vine phenology, which is responsible for the delay in vine growth at altitude.

In conclusion, Sentinel-2 was useful for monitoring vineyards on a regional scale, as a single image could capture all vineyards at the same time and under the same atmospheric conditions. Sentinel-2 multispectral data are convenient and freely available, with a temporal resolution suitable for monitoring and assessing vine growth. The spatial resolution of the initial Sentinel-2 data $(10 \mathrm{~m})$ provided average statistical values at the scale of all vineyard plots, which was sufficient to monitor dynamic vegetation responses to management and tillage applications.

Remote sensing is also a method used to monitor reclamation vegetation in grassland mining areas, as studied by [11] in their review. Due to the large size of the mining areas and the difficulties of transportation, this method is very advantageous. The most common method is to calculate various vegetation indices (from Sentinel 2 and Landsat data) that reflect ground vegetation cover based on the reflectivity of each waveband.

Since Sentinel data have the advantages of a short revisit period and high spatial resolution, surface vegetation monitoring based on Sentinel data has become a popular research topic. Many researchers have been interested in it and have developed indices adapted to it [12] proposed an NSSI vegetation index adapted to Sentinel data [11] proposed the NDVI705 vegetation index based on the red band of the Sentinel data and used it to study vegetation recovery after the Cyprus fire, [13] used Sentinel data to compute a variety of vegetation indices and used them to invert the surface salinity)

Precision measurement technologies can be applied to pasture management and are of great interest for the future sustainability of grass-based animal production systems. Indeed, it is possible to increase pasture production in a sustainable way by measuring the quantity and quality of pasture more accurately, which is what [14] were looking for. [15] explained how Sentinel-2 data could be used to predict herbage mass (HM) with comparable accuracy to hyperspectral detection on South African experimental grassland plots. Nevertheless, poor results were obtained using Sentinel-2 data on Irish grassland plots. The study showed that the main limitation of satellite spectral detection over Irish grasslands is the frequent cloud cover. Data acquisition was therefore not possible on days when cloud cover exceeded 30\%. Synthetic Aperture Radar (SAR) is an alternative technology for satellite remote sensing of pastures as it is not limited by cloud cover. It uses high-resolution radio wave reflectance to predict pasture height. Barrett et al used SAR to overcome the limitations of cloud cover for satellite classification of Irish grasslands. A more recent study using SAR over Irish dairy pastures showed promising results for both grass height and HM at $25 \mathrm{~cm}$ spatial resolution. However, research into this technology used for grasslands is still in its infancy and needs to be continued.

\subsection{EO4Agri recommendations and conclusions}

As identified by EO4Agri [16], [17], there is a need for increased agricultural production globally in the future that is of higher quality while using less land and fewer inputs at the same time. Earth observation can provide relevant information to address these challenges at local, national and global levels. Agriculture today is a complex activity involving many actors and stakeholders in agri-food chains that produce and deliver food and agricultural commodities to consumers. In addition to farmers, there are suppliers of agricultural inputs, processors, transporters and market intermediaries, all of whom have a role to play in making these chains efficient. Given the complexity of the issue, there is a need to better understand all the processes involved and to build a new knowledge management system for each agricultural sector. Earth observations can be considered as one source of data for better knowledge management systems. Earth observation is used to monitor and assess the status of changes in nature and the built environment. During the analysis, a set of data themes needed for each stakeholder group was identified and these data themes are listed in Table 1.

Table 1. Data needs for each stakeholder group Main requirements of
the Agri-Food group
Data on the weather forecast

Data for agricultural yields forecasting

Data for soil water index 
Data for providing a drought early warning system.

Data for producing maps of basic fertilizers

Data for production maps of fertilizer in the phenophase 30-34

Data for determining heights of crops

Data for estimating the extent of diseases or damages (losses)

Data for monitoring hydrological stresses

Data for producing exact information about climatic changes

\section{Main requirements of the Financial sector}

\section{Main requirements of the Public sector}

\begin{tabular}{l}
\hline $\begin{array}{l}\text { Data for identification parcels for potential land for biomass } \\
\text { production }\end{array}$ \\
\hline Data for creating flood maps (for $Q 5,25,50,100$ years) \\
\hline Data for annual soil erosion risk maps \\
\hline Data to produce maps of the occurrence of diseases \\
\hline $\begin{array}{l}\text { Data for the production of actual calamities map (droughts, flood, } \\
\text { fires, earthquakes, ...) }\end{array}$ \\
\hline $\begin{array}{l}\text { Data for production maps of relevant information for biofuel } \\
\text { production }\end{array}$ \\
\hline Data for determination productivity of grassland and pastures.
\end{tabular}

Data for support of the Common Agricultural Policy new 'greening' rules, crop, ecologically sensitive areas

Data for the identification of crops to control subsidies

Data for water protection against nitrates

Data for monitoring of the implementation of natural water retention measures

Data for mapping parcels and validation of acreage parcels $<0,5$ ha

Data for updating the Land Parcel Identification System (LPIS)

Data for monitoring phenology of grassland (number of cuts/grazing events per season)

Data for the production of crop growing calendar for agricultural monitoring

Data for yield modelling for food security

Data for food security information 


\section{Main requirements of Food and Nutrition Security}

Data for cross-border land monitoring, given the interconnection of environmental problems and food security

Data for near real-time vegetation biomass measurements for agriculture and food security during the cropping season

Data for early warning information for food security

\subsection{Objective of the paper}

The main objective of this paper is to compare the results and recommendations of EO4Agri with the analysis of literature sources, to identify gaps and to prepare a list of potential research tasks in this area for the next period. We have analysed to what depth the needs identified in the EO4Agri project are addressed in these papers and what are their main themes.

\section{Materials and Methods}

\subsection{Methods of analysis}

There are a large number of publications on the use of remote sensing for agriculture. In order to simplify the analysis, we focused on publications in MDPI and, due to the large number of publications, we decided to analyse only the most recent publications from the last year. We also used Google Scholar as a source for the search. This helps us to reduce the number of publications and also makes it easier to search for publications. In our analysis, we look at all the numbers of publications that deal with each topic. For each topic, we analyzed the number of publications and also reached an in-depth analysis of the most relevant articles.

\subsection{Deap Literature analysis}

Table 2. Deep literature analysis

\begin{tabular}{|l|c|c|}
\hline EO4Agri analysis & $\begin{array}{c}\text { Number of publications } \\
\text { analysed in MDPI }\end{array}$ & Most relevant papers \\
\hline Data on the weather forecast & 1890 & [18], [19], [20], [21] \\
\hline Data for agricultural yields forecasting & 670 & [22], [23], [24], [25] \\
\hline Data for soil water index & 2640 & [24], [26] \\
\hline Data for providing a drought early warning system. & 216 & [27], [28], [29], [30] \\
\hline Data for producing maps of basic fertilizers & 1600 & [32], [33], [34], [35] \\
\hline $\begin{array}{l}\text { Data for production maps of fertilizer in the phenophase } \\
30-34\end{array}$ & 3 & [36], [37] \\
\hline Data for determining heights of crops & 846 & [38], [39], [40] \\
\hline $\begin{array}{l}\text { Data for estimating the extent of diseases or damages } \\
\text { (losses) }\end{array}$ & 2850 & [18], [41], [42], [43], [44] \\
\hline Data for monitoring hydrological stresses & 426 & \\
\hline $\begin{array}{l}\text { Data for producing exact information about climatic } \\
\text { changes }\end{array}$ & 2650 & \\
\hline
\end{tabular}




\begin{tabular}{|c|c|c|}
\hline $\begin{array}{l}\text { Data for identification parcels for potential land for } \\
\text { biomass production }\end{array}$ & 146 & - \\
\hline Data for creating flood maps (for Q5,25,50,100years) & 1230 & {$[45],[46],[47]$} \\
\hline Data for annual soil erosion risk maps & $\begin{array}{l}250 \text { if special search "soil } \\
\text { erosion" }\end{array}$ & [48], [49] \\
\hline Data to produce maps of the occurrence of diseases & 1750 special search & {$[50],[51]$} \\
\hline $\begin{array}{l}\text { Data for the production of actual calamities map } \\
(\text { droughts, flood, fires, earthquakes, ...) }\end{array}$ & 37 & {$[45],[52],[53]$} \\
\hline $\begin{array}{l}\text { Data for production maps of relevant information for } \\
\text { biofuel production }\end{array}$ & 248 & {$[54],[55],[56],[57]$} \\
\hline $\begin{array}{l}\text { Data for determining productivity of grassland and } \\
\text { pastures. }\end{array}$ & 205 & {$[58],[59],[60]$} \\
\hline $\begin{array}{l}\text { Data for support of the Common Agricultural Policy new } \\
\text { 'greening' rules, crop, ecologically sensitive areas }\end{array}$ & 127 & {$[61]$} \\
\hline Data for the identification of crops to control subsidies & 1110 & - \\
\hline Data for water protection against nitrates & 1130 & {$[62],[63]$} \\
\hline $\begin{array}{l}\text { Data for monitoring of the implementation of natural } \\
\text { water retention measures }\end{array}$ & 109 & {$[64],[65],[66]$} \\
\hline $\begin{array}{l}\text { Data for mapping parcels and validation of acreage } \\
\text { parcels }<0,5 \text { ha }\end{array}$ & 222 & [67] \\
\hline & 2730 all literature & - \\
\hline $\begin{array}{l}\text { Data for updating the Land Parcel Identification System } \\
\text { (LPIS) }\end{array}$ & 36 & - \\
\hline $\begin{array}{l}\text { Data for monitoring phenology of grassland (number of } \\
\text { cuts/grazing events per season) }\end{array}$ & 10 & - \\
\hline $\begin{array}{l}\text { Data for the production of crop growing calendar for } \\
\text { agricultural monitoring }\end{array}$ & 813 & {$[68],[69],[70]$} \\
\hline Data for yield modelling for food security & 2880 & [71] \\
\hline Data for food security information & 1460 & {$[43],[72],[73]$} \\
\hline $\begin{array}{l}\text { Data for cross-border land monitoring, given the } \\
\text { interconnection of environmental problems and food } \\
\text { security }\end{array}$ & 59 & {$[43]$} \\
\hline $\begin{array}{l}\text { Data for near real-time vegetation biomass measurements } \\
\text { for agriculture and food security during the cropping } \\
\text { season }\end{array}$ & 123 & - \\
\hline Data for early warning information for food security & 1280 & {$[43],[44],[72],[73]$} \\
\hline
\end{tabular}

\section{Results}




\subsection{What tell us literature analysis in comparison with EO4Agri conclusion}

The high number of publications shows that the recommendations highlighted in the EO4Agri analysis are of high priority for the scientific community. It shows that these topics have been recognised by both the user and scientific communities. As such, the topics that are the hottest are:

- Data on the weather forecast

- Data for soil water index

- Data for producing maps of basic fertilizers

- Data for estimating the extent of diseases or damages (losses)

- Data for producing exact information about climatic changes

- Data for creating flood maps (for Q5,25,50,100years)

- Data to produce maps of the occurrence of diseases

- Data for the identification of crops to control subsidies

- Data for water protection against nitrates

- Data for yield modelling for food security

- Data for food security information

- Data for early warning information for food security

Although we have used a limited number of journals, it is clear that these topics are currently research priorities as all of this number of publications are from last year.

On the opposite side of research priorities were:

- Data for providing a drought early warning system.

- Data for production maps of fertilizer in the phenophase 30-34

- Data for identification parcels for potential land for biomass production

- Data for annual soil erosion risk maps

- Data for the production of actual calamities map (droughts, flood, fires, earthquakes, ...)

- Data for determining productivity of grassland and pastures.

- Data for support of the Common Agricultural Policy new 'greening' rules, crop, ecologically sensitive areas

- Data for monitoring of the implementation of natural water retention measures

- Data for mapping parcels and validation of acreage parcels $<0,5$ ha

- Data for updating the Land Parcel Identification System (LPIS)

- Data for monitoring phenology of grassland (number of cuts/grazing events per season)

- Data for cross-border land monitoring, given the interconnection of environmental problems and food security

- Data for near real-time vegetation biomass measurements for agriculture and food security during the cropping season

If we take into account the limited accuracy of this analysis due to the limited amount of paper analyzed, we can generalize the results of this analysis in the following simple statement:

- The needs of the agri-food group are addressed fairly well in the research.

- The needs of the financial and public sectors are much less addressed. This is a very interesting fact, especially in response to the public sector services that will in the near future be related to the implementation of the Green Deal on a European scale and the Sustainable Development Goals on a global scale. It seems therefore that increased efforts by the research community will be necessary here.

- Of the topics, grassland monitoring is addressed to a very limited extent. All topics related to grasslands are treated in a minimal number of publications.

One topic in particular should be mentioned, namely the monitoring of small plots. This need has been documented in the EO4Agri analysis. Small plot monitoring is one of the key issues given that most of the agri-food sector participants are from smaller farms. 
13 In what area do you grow crops or what is the average area of your clients?

20 responses

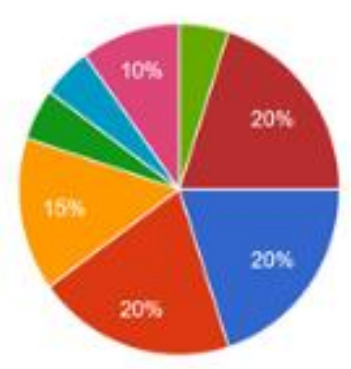

T. $105 \mathrm{ha}$

Cha to 10 ha

Tha to 30 ha

- 31ha to 60 ha

C 61 ha to 100 ha

totha to 250 ha

25tha to 500 ha

50 tha to 1000 ha

- More than 1000 ha

Figure 1. Stakeholders' Questionnaire - farm scale [17]

Most users need higher resolution images.

20 What spatial resolution (ground sample distance) of input data do you usually get?

48 responoes

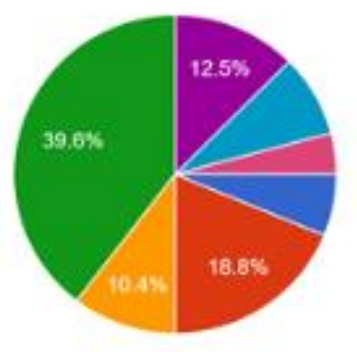

- Less than $1 \mathrm{~m}$

- 1 to $5 \mathrm{~m}$

5 to $10 \mathrm{~m}$

10 to $20 \mathrm{~m}$

20 to $30 \mathrm{~m}$

30 to $50 \mathrm{~m}$

- More than $50 \mathrm{~m}$

Figure 2. Stakeholders' Questionnaire - required image resolution [17]

This is probably related to the fact that satellites with better than $10 \mathrm{~m}$ resolution are commercial, which limits not only their use but also research activities aimed at exploiting these images.

\subsection{Sentinel-1 and Sentinel-2 data fusion}

During the INSPIRE Hackathon series [74 - 75], we documented one very important fact, namely that one of the biggest limitations of using satellite data is the availability of optical data due to cloud coverage areas. 


\section{Sentinel-2 IMAges \\ FOR ROSTENICE FARM IN 2020}

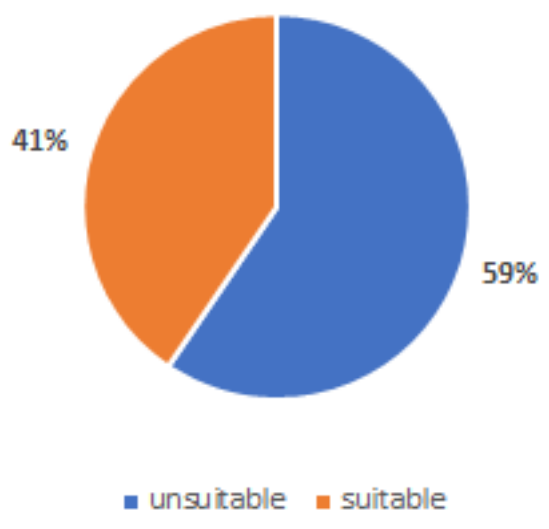

Sentinel-2 IMAgES FOR ROSTENICE FARM IN 2021

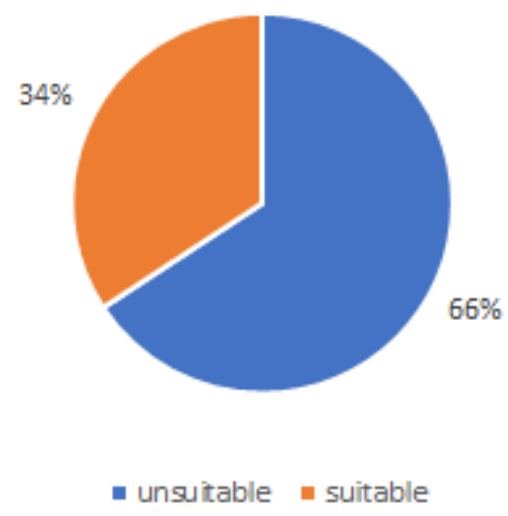

Figure 3. Availability of Sentinel 2 data for selected farm.

For this reason, the use of radar data (e.g. Sentinel 2) seems to be a high priority for the future use of satellite data in agriculture. This was the reason why we started providing in-depth analysis of papers related to the fusion of Sentinel 1 and Sentinel 2 data. The number of published papers last year was low at 61 papers in MDPI and 147 papers in total. Therefore, it follows that this topic is also under-researched and there is a research gap. In the following paragraph, we provide a deeper analysis of the most important papers.

Nowadays, Satellite monitoring of the world provides valuable data in several areas such as agriculture, hydrology, biodiversity and the environment. [76] Remote sensing images are delivered continuously and are accurate enough to monitor changes in land cover and land use around the world. For this purpose, a multitude of indices (like the Normalized Difference Vegetation Index) have been created and provide quantitative estimation of different parameters. [77 - 78] However, multispectral sensors are unusable in the presence of clouds, which make it impossible to guarantee continuous monitoring. The Sentinel-1 satellite is able to overcome this drawback, as it is equipped with Synthetic Aperture Radar (SAR) imaging sensors. Effectively combining the data and advantages of the different types of sensors would allow great progress in land cover observation.

Over the last decades, a multitude of works have used different data fusion techniques to combine the specific bands and polarisations of optical and SAR sensors. [79], [80] In this scenario, the ESA Copernicus programme has developed Sentinel missions, specifically for SAR applications, to provide a never-before-seen data continuity with the large number of satellites launched. Thus, the Sentinel-1 and Sentinel-2 missions address these issues by providing data with a higher revisit time than other satellites at a finer spatial resolution, and a higher spatial resolution than everyday sensors.

Furthermore, the application of convolutional neural network approaches in remote sensing data fusion has been promoted by a growing interest in Deep Learning. These methods are extremely valuable in global monitoring for a variety of applications. In the literature, image segmentation is addressed using different approaches:

- superpixel segmentation methods [81 - 82]

- watershed segmentation methods [83 - 84]

- level set segmentation methods [85 - 86]

- deep learning segmentation methods [87 - 88]

Crop types with similar phenological growth stages are difficult to classify and are a real challenge for Earth observation. The synergy of optical and synthetic aperture radar (SAR) data allows a broad representation of 
biophysical and structural information on target objects, thus improving the mapping of crop types. Fusion of dense multi-sensor time-series data remains complicated, however, and often poses the problem of high-dimensional feature space. [89]

\section{Discussion}

\subsection{Initial Strategic Research agenda of EO4Agri}

On the base of EO4Agri analysis [16], [89], EO4Agri recommended following research priorities

- Intra-parcel heterogeneity mapping is a widely established tool in precision agriculture for example as a basis for variable rate treatment. Further research in the domain is however encouraged and especially with regard to small fields an increase in available spatial resolution (e.g. $5 \mathrm{~m}$ ) would be highly beneficial for the analysis.

- For fertilisation and variable rate treatment an incorporation of more data sources (weather, radar, in-situ) would benefit the applications and increase precision and facilitate site specific calibration. Close collaboration with agronomists is necessary.

- In the domain of grassland (productivity) assessment/management, the cutting frequency is used as a primary proxy for land use intensity and directly policy relevant in the context of the CAP. Ground truth information and the combination of optical and radar satellites would be beneficial for the application.

- Crop sprouting is an important physiological trait for crop evaluation and nutrient management. In this field of application, remote sensing methods should always be combined with manual surveys (due to canopy density and field heterogeneity) to improve the detection.

- The generation of Crop growing calendars remains a challenge especially in areas with multiple cropping cycles that are highly heterogeneous. Therefore, a pure satellite-based method for detecting reliable crop growing dates is difficult, since a long-term analysis requires a very good crop type identification as a prerequisite (due to crop type rotation), which needs proper in-situ data for calibration and validation.

- Although the analysis of crop diseases seems possible from a scientific point of view, it is still only moderately available as a service for farmers. The spatial, as well as temporal resolution, are limiting factors. Furthermore, more precise ground-truth data and other in-situ data would be beneficial.

- The measurement of crop heights is available with UAV and SAR data. The use of UAV data prohibits its costeffective use over an extended area. The implementation is also extremely dependent on the crop type and further research is needed. It would also greatly benefit from more available in-situ data.

- Soil moisture / Soil Water is mostly required on a field or intra-field level which is not yet available. Additional research, as well as more refined in-situ data, is missing. Furthermore, the accuracy of the retrieved soil moisture still needs to be improved to minimize uncertainties. The generation of long-term high-resolution soil moisture products has also been identified as a need and can be achieved by a fusion of multiple datasets. Emphasis should also be laid on maintaining the current operational satellite-based soil moisture products, to keep the consistency with subsequent initiatives.

- For food security, greater availability and simplified comparison of the different services are desirable for increased uptake by end users. For small fields VHR data is desirable.

- An additional benefit on land surface in-situ data is to develop robust policies and strategies for food management

- For drought monitoring, better handling of in-situ data is recommended. Furthermore, better operationalisation of these services seems possible. A better prediction of yield is needed and the time between the emergence of scientific research and implementation as operational activities needs to be lowered.

\subsection{Identified GAPS in current research abains EO4Agri Strategic Research Agenda.}

In general, all EO4Agri recommendations seem valid in terms of the literature analysis. However, further research needs to be stimulated in areas that are not adequately addressed in the current literature. It is clear that probably not all research in this area is published as scientific research, but the basic research gaps seem to be evident. We can mention, for example:

- Based on an analysis of the current research in the literature, we identified one of the largest gaps as research focused on the use of satellites with 5-meter resolution and better. This seems to be important for the widespread use of EO data for small and medium farmers and especially for farmers in developing countries. 
There is a need to provide further research with commercial data and to address the opportunities and benefits of these data and the services developed that will economically benefit small and medium farmers. Having such services will also be necessary to reduce the negative environmental impacts of agriculture. There is therefore a real need to stimulate such research because only a large number of services using VHR data can reduce the cost of these data and services and make their use economically viable.

- Another important topic is to stimulate further research on the use of radar data (in the Copernicus data Sentinel 1 programme). These services can provide information for all agricultural sectors in all seasons.

- It is important to stimulate further research on environmental and public sector services. This includes services such as grassland monitoring, better use of marginal lands, biodiversity services and other services. This will be important for the implementation of the Green Deal at European level, but also for policy decisions. Building Earth oriented digital twins can improve policy decisions and the building of new strategies.

\section{Supplementary Materials: Not applicable.}

Author Contributions: For research articles with several authors, a short paragraph specifying their individual contributions must be provided. The following statements should be used "Conceptualization, Karel Charvat; methodology, Karel Charvat; formal analysis, Vincent Onckelet; investigation, Vincent Onckelet; resources, Hana Kubickova; data curation, Vincent Onckelet; writingoriginal draft preparation Karel Charvat, Vincent Onckelet; writing-review and editing, Hana Kubickova; supervision, Karel Charvat; project administration, Hana Kubickova; funding acquisition, Hana Kubickova All authors have read and agreed to the published version of the manuscript." Please turn to the CRediT taxonomy for the term explanation. Authorship must be limited to those who have contributed substantially to the work reported.

Funding: This research was funded by EO4Agri, grant number 821940 and SmartAgriHubs, grant number 818182.

Data Availability Statement: Not applicable.

Acknowledgments: Not applicable.

Conflicts of Interest: The authors declare no conflict of interest.

\section{References}

1. The Intergovernmental Panel of Climate Change, Available online: https://www.ipcc.ch/reports/ (accessed on 25 November 2021)

2. Vázquez-Jiménez, R., Romero-Calcerrada, R., Ramos-Bernal, R. N., Arrogante-Funes, P., \& Novillo, C. J. (2021). An Alternative Method for the Generation of Consistent Mapping to Monitoring Land Cover Change: A Case Study of Guerrero State in Mexico. Land, 10(7), 731.

3. Khechba, K., Laamrani, A., Dhiba, D., Misbah, K., \& Chehbouni, A. (2021). Monitoring and Analyzing Yield Gap in Africa through Soil Attribute Best Management Using Remote Sensing Approaches: A Review. Remote Sensing, 13(22), 4602.

4. Charudattan, R. (2001). Biological control of weeds by means of plant pathogens: Significance for integrated weed management in modern agro-ecology. BioControl, 46(2), 229-260. doi:10.1023/A:1011477531101

5. Ammoniaci, M., Kartsiotis, S.-P., Perria, R., \& Storchi, P. (2021). State of the Art of Monitoring Technologies and Data Processing for Precision Viticulture. Agriculture, 11(3), 201.

6. Pierce, F. J., \& Nowak, P. (1999). Aspects of Precision Agriculture. In D. L. Sparks (Ed.), Advances in Agronomy (Vol. 67, pp. 185): Academic Press.

7. Liang, L. (2019). Phenology. In Reference Module in Earth Systems and Environmental Sciences: Elsevier.

8. Rahman, M. S., \& Di, L. (2020). A Systematic Review on Case Studies of Remote-Sensing-Based Flood Crop Loss Assessment. Agriculture, 10(4), 131.

9. Rahman, M. S., Di, L., Yu, E., Lin, L., Zhang, C., \& Tang, J. (2019). Rapid Flood Progress Monitoring in Cropland with NASA SMAP. Remote Sensing, 11(2), 191.

10. Tassopoulos, D., Kalivas, D., Giovos, R., Lougkos, N., \& Priovolou, A. (2021). Sentinel-2 Imagery Monitoring Vine Growth Related to Topography in a Protected Designation of Origin Region. Agriculture, 11(8), 785.

11. Hui, J., Bai, Z., Ye, B., \& Wang, Z. (2021). Remote Sensing Monitoring and Evaluation of Vegetation Restoration in Grassland Mining Areas-A Case Study of the Shengli Mining Area in Xilinhot City, China. Land, 10(7), 743.

12. Tian, J., Su, S., Tian, Q., Zhan, W., Xi, Y., \& Wang, N. (2021). A novel spectral index for estimating fractional cover of nonphotosynthetic vegetation using near-infrared bands of Sentinel satellite. International Journal of Applied Earth Observation and Geoinformation, 101, 102361. doi:https://doi.org/10.1016/j.jag.2021.102361

13. Ramos, T. B., Castanheira, N., Oliveira, A. R., Paz, A. M., Darouich, H., Simionesei, L., . . Gonçalves, M. C. (2020). Soil salinity assessment using vegetation indices derived from Sentinel-2 multispectral data. application to Lezíria Grande, Portugal. Agricultural Water Management, 241, 106387. doi:https://doi.org/10.1016/j.agwat.2020.106387 
14. Murphy, D. J., Murphy, M. D., O’Brien, B., \& O’Donovan, M. (2021). A Review of Precision Technologies for Optimising Pasture Measurement on Irish Grassland. Agriculture, 11(7), 600.

15. Sibanda, M., Mutanga, O., \& Rouget, M. (2016). Comparing the spectral settings of the new generation broad and narrow band sensors in estimating biomass of native grasses grown under different management practices. GIScience E Remote Sensing, 53(5), 614-633. doi:10.1080/15481603.2016.1221576

16. EO4Agri D6.6 Strategic Research Agenda Report. DOI:10.13140/RG.2.2.26922.34242

17. Šafář, V., Charvat, K., Bye, B.L., Kolitzus, D., Rimgaila, M., Horakova, S. and Esbrí Palomares, M. (2019) EO4AGRI D2.2-InitialWorkshop-User-Requirements-and-Gap-Analysis-in-Different-Sectors-Report-v1.0, 10.13140/RG.2.2.15466.26565

18. Barasa, P.M.; Botai, C.M.; Botai, J.O.; Mabhaudhi, T. A Review of Climate-Smart Agriculture Research and Applications in Africa. Agronomy 2021, 11, 1255. https://doi.org/10.3390/agronomy11061255

19. Barasa, P.M.; Botai, C.M.; Botai, J.O.; Mabhaudhi, T. A Review of Climate-Smart Agriculture Research and Applications in Africa. Agronomy 2021, 11, 1255. https://doi.org/10.3390/agronomy11061255

20. Panchasara, H.; Samrat, N.H.; Islam, N. Greenhouse Gas Emissions Trends and Mitigation Measures in Australian Agriculture Sector-A Review. Agriculture 2021, 11, 85. https://doi.org/10.3390/agriculture11020085

21. Maraveas, C.; Bartzanas, T. Application of Internet of Things (IoT) for Optimized Greenhouse Environments. AgriEngineering 2021, 3, 954-970. https://doi.org/10.3390/agriengineering3040060

22. Khan, N.; Kamaruddin, M.A.; Sheikh, U.U.; Yusup, Y.; Bakht, M.P. Oil Palm and Machine Learning: Reviewing One Decade of Ideas, Innovations, Applications, and Gaps. Agriculture 2021, 11, 832. https://doi.org/10.3390/agriculture11090832

23. Barriguinha, A.; de Castro Neto, M.; Gil, A. Vineyard Yield Estimation, Prediction, and Forecasting: A Systematic Literature Review. Agronomy 2021, 11, 1789. https://doi.org/10.3390/agronomy11091789

24. Anderson, N.T.; Walsh, K.B.; Wulfsohn, D. Technologies for Forecasting Tree Fruit Load and Harvest Timing - From Ground, Sky and Time. Agronomy 2021, 11, 1409. https://doi.org/10.3390/agronomy11071409

25. Monteiro, A.I.; Malheiro, A.C.; Bacelar, E.A. Morphology, Physiology and Analysis Techniques of Grapevine Bud Fruitfulness: A Review. Agriculture 2021, 11, 127. https://doi.org/10.3390/agriculture11020127

26. Giordano, M.; Petropoulos, S.A.; Rouphael, Y. Response and Defence Mechanisms of Vegetable Crops against Drought, Heat and Salinity Stress. Agriculture 2021, 11, 463. https://doi.org/10.3390/agriculture11050463

27. van Ginkel, M.; Biradar, C. Drought Early Warning in Agri-Food Systems. Climate 2021, 9, 134. https://doi.org/10.3390/cli9090134

28. Orimoloye, I.R.; Zhou, L.; M. Kalumba, A. Drought Disaster Risk Adaptation through Ecosystem Services-Based Solutions: Way Forward for South Africa. Sustainability 2021, 13, 4132. https://doi.org/10.3390/su13084132

29. Wen, W.; Timmermans, J.; Chen, Q.; van Bodegom, P.M. A Review of Remote Sensing Challenges for Food Security with Respect to Salinity and Drought Threats. Remote Sens. 2021, 13, 6. https://doi.org/10.3390/rs13010006

30. Varghese, D.; Radulović, M.; Stojković, S.; Crnojević, V. Reviewing the Potential of Sentinel-2 in Assessing the Drought. Remote Sens. 2021, 13, 3355. https://doi.org/10.3390/rs13173355

31. Onyango, C.M.; Nyaga, J.M.; Wetterlind, J.; Söderström, M.; Piikki, K. Precision Agriculture for Resource Use Efficiency in Smallholder Farming Systems in Sub-Saharan Africa: A Systematic Review. Sustainability 2021, 13 , 1158. https://doi.org/10.3390/su13031158

32. Roslim, M.H.M.; Juraimi, A.S.; Che'YYa, N.N.; Sulaiman, N.; Manaf, M.N.H.A.; Ramli, Z.; Motmainna, M. Using Remote Sensing and an Unmanned Aerial System for Weed Management in Agricultural Crops: A Review. Agronomy 2021, $11,1809$. https://doi.org/10.3390/agronomy11091809

33. Monteiro, A.; Santos, S.; Gonçalves, P. Precision Agriculture for Crop and Livestock Farming - Brief Review. Animals 2021, 11, 2345. https://doi.org/10.3390/ani11082345

34. Mohidem, N.A.; Che'Ya, N.N.; Juraimi, A.S.; Fazlil Ilahi, W.F.; Mohd Roslim, M.H.; Sulaiman, N.; Saberioon, M.; Mohd Noor, N. How Can Unmanned Aerial Vehicles Be Used for Detecting Weeds in Agricultural Fields? Agriculture 2021, $11,1004$. https://doi.org/10.3390/agriculture11101004

35. Niu, Y.; Chen, T.; Zhao, C.; Zhou, M. Improving Crop Lodging Resistance by Adjusting Plant Height and Stem Strength. Agronomy 2021, 11, 2421. https://doi.org/10.3390/agronomy11122421

36. Tudi, M.; Daniel Ruan, H.; Wang, L.; Lyu, J.; Sadler, R.; Connell, D.; Chu, C.; Phung, D.T. Agriculture Development, Pesticide Application and Its Impact on the Environment. Int. J. Environ. Res. Public Health 2021, 18 , 1112. $\underline{\text { https://doi.org/10.3390/ijerph18031112 }}$

37. Bertaccini, A. Containment of Phytoplasma-Associated Plant Diseases by Antibiotics and Other Antimicrobial Molecules. Antibiotics 2021, 10, 1398. https://doi.org/10.3390/antibiotics10111398

38. Mojid, M.A.; Mainuddin, M. Water-Saving Agricultural Technologies: Regional Hydrology Outcomes and Knowledge Gaps in the Eastern Gangetic Plains - A Review. Water 2021, 13, 636. https://doi.org/10.3390/w13050636

39. Dimitriadou, S.; Nikolakopoulos, K.G. Evapotranspiration Trends and Interactions in Light of the Anthropogenic Footprint and the Climate Crisis: A Review. Hydrology 2021, 8, 163. https://doi.org/10.3390/hydrology8040163

40. Wang, D.; Hubacek, K.; Shan, Y.; Gerbens-Leenes, W.; Liu, J. A Review of Water Stress and Water Footprint Accounting. Water 2021, 13, 201. https://doi.org/10.3390/w13020201

41. Bozzo, G.; Corrente, M.; Testa, G.; Casalino, G.; Dimuccio, M.M.; Circella, E.; Brescia, N.; Barrasso, R.; Celentano, F.E. Animal Welfare, Health and the Fight against Climate Change: One Solution for Global Objectives. Agriculture 2021, $11,1248$. https://doi.org/10.3390/agriculture11121248 
42. Agüera, E.; de la Haba, P. Climate Change Impacts on Sunflower (Helianthus annus L.) Plants. Plants $2021,10,2646$. https://doi.org/10.3390/plants10122646

43. Stavi, I.; Paschalidou, A.; Kyriazopoulos, A.P.; Halbac-Cotoara-Zamfir, R.; Siad, S.M.; Suska-Malawska, M.; Savic, D.; Roque de Pinho, J.; Thalheimer, L.; Williams, D.S.; Hashimshony-Yaffe, N.; van der Geest, K.; Cordovil, C.M.d.S.; Ficko, A. Multidimensional Food Security Nexus in Drylands under the Slow Onset Effects of Climate Change. Land 2021, $10,1350$. https://doi.org/10.3390/land10121350

44. Liu, W.; Chen, Y.; He, X.; Mao, P.; Tian, H. Is Current Research on How Climate Change Impacts Global Food Security Really Objective? Foods 2021, 10, 2342. https://doi.org/10.3390/foods10102342

45. Amarnath, G.; Amarasinghe, U.A.; Alahacoon, N. Disaster Risk Mapping: A Desk Review of Global Best Practices and Evidence for South Asia. Sustainability 2021, 13, 12779. https://doi.org/10.3390/su132212779

46. Munawar, H.S.; Hammad, A.W.A.; Waller, S.T.; Thaheem, M.J.; Shrestha, A. An Integrated Approach for Post-Disaster Flood Management Via the Use of Cutting-Edge Technologies and UAVs: A Review. Sustainability 2021, $13,7925$. https://doi.org/10.3390/su13147925

47. Diaconu, D.C.; Costache, R.; Popa, M.C. An Overview of Flood Risk Analysis Methods. Water $2021,13,474$. https://doi.org/10.3390/w13040474

48. Raza, A.; Ahrends, H.; Habib-Ur-Rahman, M.; Gaiser, T. Modeling Approaches to Assess Soil Erosion by Water at the Field Scale with Special Emphasis on Heterogeneity of Soils and Crops. Land 2021, 10, 422. https://doi.org/10.3390/land10040422

49. Niacsu, L.; Ionita, I.; Samoila, C.; Grigoras, G.; Blebea-Apostu, A.M. Land Degradation and Soil Conservation Measures in the Moldavian Plateau, Eastern Romania: A Case Study from the Racova Catchment. Water 2021, $13,2877$. https://doi.org/10.3390/w13202877

50. Sun, T.; Liu, Y.; Qin, X.; Aspridou, Z.; Zheng, J.; Wang, X.; Li, Z.; Dong, Q. The Prevalence and Epidemiology of Salmonella in Retail Raw Poultry Meat in China: A Systematic Review and Meta-Analysis. Foods 2021, $10,2757$. https://doi.org/10.3390/foods10112757

51. Olivares, B.O.; Rey, J.C.; Lobo, D.; Navas-Cortés, J.A.; Gómez, J.A.; Landa, B.B. Fusarium Wilt of Bananas: A Review of AgroEnvironmental Factors in the Venezuelan Production System Affecting Its Development. Agronomy 2021, $11,986$. https://doi.org/10.3390/agronomy11050986

52. Abid, S.K.; Sulaiman, N.; Chan, S.W.; Nazir, U.; Abid, M.; Han, H.; Ariza-Montes, A.; Vega-Muñoz, A. Toward an Integrated Disaster Management Approach: How Artificial Intelligence Can Boost Disaster Management. Sustainability 2021, $13,12560$. https://doi.org/10.3390/su132212560

53. Daher, B.; Hamie, S.; Pappas, K.; Nahidul Karim, M.; Thomas, T. Toward Resilient Water-Energy-Food Systems under Shocks: Understanding the Impact of Migration, Pandemics, and Natural Disasters. Sustainability 2021, $13,9402$. https://doi.org/10.3390/su13169402

54. Khan, H.M.; Iqbal, T.; Yasin, S.; Ali, C.H.; Abbas, M.M.; Jamil, M.A.; Hussain, A.; M. Soudagar, M.E.; Rahman, M.M. Application of Agricultural Waste as Heterogeneous Catalysts for Biodiesel Production. Catalysts 2021, $11,1215$. https://doi.org/10.3390/catal11101215

55. Bharti, A.; Paritosh, K.; Mandla, V.R.; Chawade, A.; Vivekanand, V. GIS Application for the Estimation of Bioenergy Potential from Agriculture Residues: An Overview. Energies 2021, 14, 898. https://doi.org/10.3390/en14040898

56. Petrokofsky, G.; Harvey, W.J.; Petrokofsky, L.; Ochieng, C.A. The Importance of Time-Saving as a Factor in Transitioning from Woodfuel to Modern Cooking Energy Services: A Systematic Map. Forests 2021, 12, 1149. https://doi.org/10.3390/f12091149

57. Haberzettl, J.; Hilgert, P.; von Cossel, M. A Critical Review on Lignocellulosic Biomass Yield Modeling and the Bioenergy Potential from Marginal Land. Agronomy 2021, 11, 2397. https://doi.org/10.3390/agronomy11122397

58. Ghajar, S.; Tracy, B. Proximal Sensing in Grasslands and Pastures. Agriculture 2021, 11, 740. https://doi.org/10.3390/agriculture11080740

59. Murphy, D.J.; Murphy, M.D.; O’Brien, B.; O’Donovan, M. A Review of Precision Technologies for Optimising Pasture Measurement on Irish Grassland. Agriculture 2021, 11, 600. https://doi.org/10.3390/agriculture11070600

60. Jaramillo, D.M.; Sheridan, H.; Soder, K.; Dubeux, J.C.B., Jr. Enhancing the Sustainability of Temperate Pasture Systems through More Diverse Swards. Agronomy 2021, 11, 1912. https://doi.org/10.3390/agronomy11101912

61. Fusco, G. Twenty Years of Common Agricultural Policy in Europe: A Bibliometric Analysis. Sustainability 2021, $13,10650$. https://doi.org/10.3390/su131910650

62. Vinci, G.; Maddaloni, L.; Mancini, L.; Prencipe, S.A.; Ruggeri, M.; Tiradritti, M. The Health of the Water Planet: Challenges and Opportunities in the Mediterranean Area. An Overview. Earth 2021, 2, 894-919. https://doi.org/10.3390/earth2040052

63. Akhter, F.; Siddiquei, H.R.; Alahi, M.E.E.; Mukhopadhyay, S.C. Recent Advancement of the Sensors for Monitoring the Water Quality Parameters in Smart Fisheries Farming. Computers 2021, 10, 26. https://doi.org/10.3390/computers10030026

64. Imfeld, G.; Payraudeau, S.; Tournebize, J.; Sauvage, S.; Macary, F.; Chaumont, C.; Probst, A.; Sánchez-Pérez, J.-M.; Bahi, A.; Chaumet, B.; Gilevska, T.; Alexandre, H.; Probst, J.-L. The Role of Ponds in Pesticide Dissipation at the Agricultural Catchment Scale: A Critical Review. Water 2021, 13, 1202. https://doi.org/10.3390/w13091202

65. Li, S. Landscape Integrated Soil and Water Conservation (LISWC) System for Sloping Landscapes in Atlantic Canada. Agriculture 2021, 11, 427. https://doi.org/10.3390/agriculture11050427

66. Pinheiro Machado Filho, L.C.; Seó, H.L.S.; Daros, R.R.; Enriquez-Hidalgo, D.; Wendling, A.V.; Pinheiro Machado, L.C. Voisin Rational Grazing as a Sustainable Alternative for Livestock Production. Animals 2021, $11,3494$. https://doi.org/10.3390/ani11123494 
67. Ntihinyurwa, P.D.; de Vries, W.T. Farmland Fragmentation, Farmland Consolidation and Food Security: Relationships, Research Lapses and Future Perspectives. Land 2021, 10, 129. https://doi.org/10.3390/land10020129

68. Fan, D.; Su, X.; Weng, B.; Wang, T.; Yang, F. Research Progress on Remote Sensing Classification Methods for Farmland Vegetation. AgriEngineering 2021, 3, 971-989. https://doi.org/10.3390/agriengineering3040061

69. Pluto-Kossakowska, J. Review on Multitemporal Classification Methods of Satellite Images for Crop and Arable Land Recognition. Agriculture 2021, 11, 999. https://doi.org/10.3390/agriculture11100999

70. Khan, N.; Ray, R.L.; Kassem, H.S.; Hussain, S.; Zhang, S.; Khayyam, M.; Ihtisham, M.; Asongu, S.A. Potential Role of Technology Innovation in Transformation of Sustainable Food Systems: A Review. Agriculture 2021, 11, 984. https://doi.org/10.3390/agriculture11100984

71. Khechba, K.; Laamrani, A.; Dhiba, D.; Misbah, K.; Chehbouni, A. Monitoring and Analyzing Yield Gap in Africa through Soil Attribute Best Management Using Remote Sensing Approaches: A Review. Remote Sens. $2021,13,4602$. https://doi.org/10.3390/rs13224602

72. Rochefort, G.; Lapointe, A.; Mercier, A.-P.; Parent, G.; Provencher, V.; Lamarche, B. A Rapid Review of Territorialized Food Systems and Their Impacts on Human Health, Food Security, and the Environment. Nutrients 2021, $13,3345$. https://doi.org/10.3390/nu13103345

73. Bonatti, M.; Borba, J.; Löhr, K.; Tremblay, C.; Sieber, S. Social Learning and Paulo Freire Concepts for Understanding Food Security Cases in Brazil. Agriculture 2021, 11, 807. https://doi.org/10.3390/agriculture11090807

74. Charvat, K., Bye, B. L., Kubickova, H., Zampati, F., Löytty, T., Odhiambo, K., ... \& Kamau, W. (2021). Capacity Development and Collaboration for Sustainable African Agriculture: Amplification of Impact Through Hackathons. Data Science Journal, 20(1).

75. Charvat, K., Bye, B. L., Mildorf, T., Berre, A. J., \& Jedlicka, K. (2018). Open data, VGI and citizen observatories INSPIRE hackathon. International Journal of Spatial Data Infrastructures Research, 13, 109-130.

76. Gargiulo, M., Dell'Aglio, D. A. G., Iodice, A., Riccio, D., \& Ruello, G. (2020). Integration of Sentinel-1 and Sentinel-2 Data for Land Cover Mapping Using W-Net. Sensors, 20(10), 2969.

77. Carlson, T. N., \& Ripley, D. A. (1997). On the relation between NDVI, fractional vegetation cover, and leaf area index. Remote Sensing of Environment, 62(3), 241-252. doi:https://doi.org/10.1016/S0034-4257(97)00104-1

78. Maselli, F., Chiesi, M., \& Pieri, M. (2019). A New Method to Enhance the Spatial Features of Multitemporal NDVI Image Series. IEEE Transactions on Geoscience and Remote Sensing, 57(7), 4967-4979. doi:10.1109/TGRS.2019.2894850

79. Scarpa, G., Gargiulo, M., Mazza, A., \& Gaetano, R. (2018). A CNN-Based Fusion Method for Feature Extraction from Sentinel Data. Remote Sensing, 10(2), 236.

80. Whyte, A., Ferentinos, K. P., \& Petropoulos, G. P. (2018). A new synergistic approach for monitoring wetlands using Sentinels -1 and 2 data with object-based machine learning algorithms. Environmental Modelling $\mathcal{E}$ Software, 104, 40-54. doi:https://doi.org/10.1016/j.envsoft.2018.01.023

81. Lang, F., Yang, J., Yan, S., \& Qin, F. (2018). Superpixel Segmentation of Polarimetric Synthetic Aperture Radar (SAR) Images Based on Generalized Mean Shift. Remote Sensing, 10(10), 1592.

82. Stutz, D., Hermans, A., \& Leibe, B. (2018). Superpixels: An evaluation of the state-of-the-art. Computer Vision and Image Understanding, 166, 1-27. doi:https://doi.org/10.1016/j.cviu.2017.03.007

83. Ciecholewski, M. (2017). River channel segmentation in polarimetric SAR images: Watershed transform combined with average contrast maximisation. Expert Systems with Applications, 82, 196-215. doi:https://doi.org/10.1016/j.eswa.2017.04.018

84. Cousty, J., Bertrand, G., Najman, L., \& Couprie, M. (2010). Watershed Cuts: Thinnings, Shortest Path Forests, and Topological Watersheds. IEEE Transactions on Pattern Analysis and Machine Intelligence, 32(5), 925-939. doi:10.1109/TPAMI.2009.71

85. Braga, A. M., Marques, R. C. P., Rodrigues, F. A. A., \& Medeiros, F. N. S. (2017). A Median Regularized Level Set for Hierarchical Segmentation of SAR Images. IEEE Geoscience and Remote Sensing Letters, 14(7), 1171-1175. doi:10.1109/LGRS.2017.2702062

86. Jin, R., Yin, J., Zhou, W., \& Yang, J. (2017). Level Set Segmentation Algorithm for High-Resolution Polarimetric SAR Images Based on a Heterogeneous Clutter Model. IEEE Journal of Selected Topics in Applied Earth Observations and Remote Sensing, 10(10), 4565-4579. doi:10.1109/JSTARS.2017.2716620

87. Zhou, Y., Wang, H., Xu, F., \& Jin, Y. (2016). Polarimetric SAR Image Classification Using Deep Convolutional Neural Networks. IEEE Geoscience and Remote Sensing Letters, 13(12), 1935-1939. doi:10.1109/LGRS.2016.2618840

88. Gargiulo, M., Dell'Aglio, D. A. G., Iodice, A., Riccio, D., \& Ruello, G. (2019, 24-26 Oct. 2019). Semantic Segmentation using Deep Learning: A case of study in Albufera Park, Valencia. Paper presented at the 2019 IEEE International Workshop on Metrology for Agriculture and Forestry (MetroAgriFor).

89. Charvat, K.; Safar, V.; Kubickova, H.; Horakova, S.; Mildorf, T. Strategic Research Agenda for Utilisation of Earth Observation in Agriculture. Eng. Proc. 2021, 9, 35. https://doi.org/10.3390/engproc2021009035 